\title{
RESEPSI KEKERASAN SEKSUAL KHALAYAK DALAM SERIAL TV GAME OF THRONES
}

\author{
Oleh: \\ Adella Vira Andiesta dan Atwar Bajari \\ Department of Communication Management, \\ Faculty of Communication Science Universitas Padjadjaran \\ E-mail: adella.andiesta@gmail.com, atwarbajari@gmail.com
}

\begin{abstract}
Abstrak
Abstrak Penelitian ini berjudul Interpretasi Pemirsa terhadap Kekerasan Seksual dalam serial TV, Game of the Thrones Penasihat Utama Dr. Atwar Bajari., M.Si. dan Penasihat Kedua Dr. Iwan Koswara., M.Si. Penelitian ini bertujuan untuk mengetahui (1) rumusan makna pembuat teks, (2) pembacaan khalayak, dan (3) kerangka pengetahuan pemirsa yang mendasari pembacaan terhadap kekerasan seksual di serual TV, Game of Thrones. Ini adalah penelitian metode kualitatif dengan teknik analisis penerimaan menggunakan model Encoding-Decoding Stuart Hall. Objek penelitiannya adalah serial TV, Game of Thrones dan informan penelitian adalah penonton serial TV Game of Thrones. Hasil penelitian ini menunjukkan bahwa rumusan pembuat teks tentang makna kekerasan seksual dapat disimpulkan hingga tiga poin. Pembacaan penonton menghasilkan ketiga posisi membaca: pembacaan dominan-hegemonik, negosiasi, dan oposisi. Kerangka pendengar pengetahuan yang mendasari bacaan itu terdiri dari aspek kepercayaan, nilai budaya, dan latar belakang pendidikan. Peneliti mengemukakan bahwa (1) produsen teks media meneliti penelitian pendengar dalam menentukan konteks media, dan (2) studi penerimaan dan penelitian dengan menggunakan metode analisis penerimaan untuk lebih ditingkatkan.
\end{abstract}

Kata kunci: Khalayak, Kekerasan seksual, Game of Throne, Analisis Penerimaan, Encoding-decoding

\begin{abstract}
This research is entitled Audience Interpretation towards Sexual Violence in the Game of Thrones TV Series. Leading Counselor Dr. Atwar Bajari.,M.Si. and Second Counselor Dr. Iwan Koswara.,M.Si.

This research aims to determine (1) the text producer's formulation of meaning, (2) the audience reading, and (3) the audience frame of knowledge that underlies the reading towards sexual violence in the Game of Thrones TV Series. This is a qualitative method research with reception analysis technique using Stuart Hall's Encoding-Decoding model. The research object is Game of Thrones TV Series and the research informant is the audience of Game of Thrones TV Series.

Results of this research show that the text producer's formulation of meaning on sexual violence can be summed up to three points. Audience readings result in all three reading positions: dominant-hegemonic, negotiated, and oppositional reading. The audience frame of knowledge that underlies the reading consists of aspects of belief, cultural values, and educational background.

Researcher suggests that (1) media text producers examine audience research in determining the media context, and (2) study of reception and research using reception analysis method to be further improved.
\end{abstract} decoding

Keywords: Khalayak, sexual violance, Game of Throne, Reception Analysis, Encoding- 


\section{A. PENDAHULUAN}

Game of Thrones adalah program televisi dari Amerika Serikat yang berhasil menarik perhatian dunia. Serial ini bergenre drama fantasi yang diaptasi dari novel seri karya George R.R. Martin berjudul A Song of Ice and Fire dan diproduksi oleh HBO dengan David Benioff dan D.B. Weiss sebagai showrunner dan penulis utama. Portal web nomor satu dalam menyediakan informasi mengenai film, televisi, dan video game di dunia, IMDb, menempatkan Game of Thrones di posisi pertama dalam kategori Most Voted TV Series dengan jumlah vote sebanyak 1,147,712 suara, mengalahkan 129,746 judul serial televisi lainnya. Selama lima tahun tayang sejak 2011 hingga saat ini, Game of Thrones bisa disebut sebagai serial televisi yang memiliki prestasi sangat baik. Lewat 12 penghargaan yang diterima pada Emmy Awards 2016, serial ini berhasil menjadi acara televisi dengan penghargaan terbanyak. Dengan total 38 piala Emmy Awards, Game of Thrones berhasil mengalahkan rekor penerima Emmy Awards terbanyak sepanjang sejarah, sitkom Fraiser, yang tayang selama 11 tahun (1993-2004) dengan total 37 penghargaan. Selain Emmy Awards, Game of Thrones juga mendapatkan 208 penghargaan lainnya - termasuk Golden Globes pada 2012 - dan 410 nominasi.

Meskipun menerima banyak pujian dari para kritikus film untuk akting, karakter yang kompleks, cerita, ruang lingkup, dan nilai-nilai produksinya, Game of Thrones kerap menuai kontroversi di berbagai kalangan. Penggambaran dunia Eropa abad pertengahan yang sarat dengan adegan kekerasan dan seks secara eksplisit ditayangkan di sebagian besar episodenya tanpa disensor. Maraknya adegan tersebut tentu menjadi pro-kontra di banyak kalangan, terlebih lagi tayangan ini dikonsumsi oleh masyarakat Indonesia yang cenderung masih lekat dengan norma-norma serta nilai yang dipercaya berdasarkan budaya ketimurannya. Sebuah hal yang menarik tentang bagaimana khalayak memberikan makna terhadap adegan seksual dan aspeknya, serta justifikasi sejauh mana yang sampai pada khalayak hasil dari produser teks media, dala hal ini yaitu kreator serial televisi Game of Thrones.

Serial Game of Thrones diwarnai konflik politik dan cinta. Berkisah di dua benua fiktif, Westeros dan Essos, serial ini mengisahkan tentang perebutan tahta Iron Throne diantara The Seven Kingdom, nama yang diberikan kepada tujuh kerajaan yang berkuasa di Westeros sebelum akhirnya terjadi penaklukan dari salah satu kerajaan, yang dikenal dengan sebutan "Penaklukan Targeryen". Persengkongkolan, pengkhianatan, pembunuhan, intrik tak berkesudahan, peperangan, hingga percintaan terlarang selalu mewarnai episode demi episode. Penyajian cerita yang sedemikian rupa mampu membuat perasaan penonton Game of Thrones bergejolak di setiap episodenya. Penonton tidak bisa menebak apa yang akan terjadi kecuali mereka membaca novelnya.

Berlatarbelakang di dunia pada masa-masa medieval, Game of Thrones sarat dengan adegan seks dan kekerasan yang secara eksplisit ditampilkan di sebagian besar scene-nya tanpa disensor. Dalam adegan-adegan yang menampakkan tubuh manusia secara gamblang, selain berhubungan badan dengan pasangannya masing-masing, beberapa adegan menampilkan tokoh pekerja seks dan pemuas hasrat. Tidak jarang terdapat unsur paksaan dan kekerasan dalam berhubungan seksual yang juga ditampilkan tanpa sensor. 
Penelitian ini masuk ke dalam kajian media dan budaya yang merupakan salah satu bagian pembelajaran dalam ranah komunikasi kajian tentang media berada dalam berbagai disiplin ilmu, baik komunikasi, gender, media, culture studies, serta sosiologi yang secara khusus tertarik kepada sifat dasar audiens, pengaruh media, representasi, teori media dalam kaitannya dengan masyarakat, kekuasaan yang diterapkan oleh institusi-institusi media terhadap masyarakat, berita dan bias, ideologi, dan ide-ide tentang bagaimana hal tersebut beroperasi lewat media.

Studi mengenai hubungan yang terjadi antara media dan khalayak menjadi perhatian utama antara industri media, akademisi, maupun pemerhati media dan masalah sosial. Media mampu menjadi stimuli individu untuk menikmati sajian pesan atau program yang ditampilkan. Isi media mampu menjadi wacana perbincangan (penerimaan khalayak) yang menarik apabila dikaitkan dengan konteks budaya dan sosial khalayak. Salah satu standar untuk mengukur khalayak media adalah dengan menggunakan reception analysis, dimana analisis ini mencoba memberikan sebuah makna atas pemahaman teks media dengan memahami bagaimana karakter teks media dibaca oleh khalayak. Teori reception memiliki argumen bahwa faktor kontekstual memengaruhi cara khalayak membaca media. Faktor kontekstual termasuk elemen identitas khalayak, persepsi penonton atas film atau genre program televisi dan produksi, bahkan termasuk latar belakang sosial, sejarah dan isu politik.

\section{B. TINJAUAN PUSTAKA}

Secara konseptual, khalayak mengonsumsi media dalam berbagai cara dan kebutuhan. Pemikiran interpretif dalam studi resepsi menekankan pada pengalaman subyektif seseorang dalam memahami suatu fenomena. Merujuk pada hal tersebut, peneliti berusaha melihat lebih dekat apa yang sebenarnya terjadi pada individu sebagai pengonsumsi teks media dan bagaimana mereka memandang dan memahami teks media tersebut secara berbeda-beda.

Peneliti mengaitkan permasalahan ini dengan model encoding-decoding dari Stuart Hall yang mengungkapkan bahwa hasil interpretasi penerima pesan belum tentu sama dengan apa yang ingin disampaikan oleh produsen pesan pada awal pembentukannya (Croteau \& Hayness, 1997: 271). Model tersebut memberi pemahaman bahwa pesan yang sama dapat dikirimkan atau diterjemahkan lebih dari satu cara, bahwa pesan selalu mengandung lebih dari satu potensi pembacaan. Tujuan pesan dan arahan pembacaan memang ada, tetapi hal tersebut tidak dapat menutup menjadi satu pembacaan saja; mereka masih bersifat polisemi.

Dalam melakukan penelitian tentunya diperlukan sebuah metodologi tertentu sehingga peneliti memiliki sebuah instrumen penelitian yang sesuai dengan khazanah keilmuan komunikasi. Dalam penelitian ini, peneliti menggunakan metodologi kualitatif yang didefinisikan Moleong (2007: 4) sebagai penelitian yang bertujuan untuk memperoleh gambaran seutuhnya mengenai suatu hal menurut pandangan manusia yang diteliti. Penelitian kualitatif berhubungan dengan ide, persepsi, pendapat atau kepercayaan orang yang diteliti dan kesemuanya tidak dapat diukut dengan angka. 
Analisis resepsi atau reception analysis bisa dikatakan sebagai perspektif baru dalam aspek wacana dan sosial dari teori komunikasi. Jensen (1999: 137) mengungkapkan, analisis resepsi menjadi pendekatan tersendiri yang mencoba mengkaji secara mendalam bagaimana proses-proses aktual melalui wacana media diasimilasikan dengan berbagai wacana dan praaktik kultural audiensnya. Analisis resepsi membahas bagaimana media dan khalayak berinteraksi satu sama lain sebagai agen. Khalayak dilihat sebagai bagian dari interpretive communitive yang selalu aktif dalam meresepsi pesan dan memproduksi makna, tidak hanya sekedar menjadi individu pasif yang menerima makna yang diproduksi oleh media massa (McQuail, 1997: 19).

Riset khalayak menurut Stuart Hall, seperti yang dikutip Baran, memiliki perhatian langsung terhadap: (a) analisis dalam konteks sosial dan politik dimana isi media diproduksi (encoding); dan (b) konsumsi isi media (decoding) dalam konteks kehidupan sehari-hari. Analisis resepsi memfokuskan perhatian pada individu dalam proses komunikasi massa (decoding), yakni proses pemaknaan dan pemahaman yang mendalam atas media texts, dan bagaimana individu menginterpretasikan isi media (Baran, 2003: 269270).

Keragaman pembacaan khalayak dalam memaknai isi siaran menurut model encoding-decoding Stuart Hall terbagi menjadi tiga bagian, yaitu posisi dominant hegemonic, negotiated, dan oppositional. Dalam penelitian ini, akan digali pemaknaan khalayak (informan) mengenai kekerasan seksual dalam serial televisi Game of Thrones dimana khalayak tidak dinilai pasif, melainkan sebagai active producers of meaning. Keragaman pembacaan khalayak yang menjadi informan dan komparasinya dengan encoding atau rumusan makna oleh produser serial akan menjadi hasil penelitian ini.

Pada setiap penelitian, terlebih analisis resepsi dimana khalayak adalah fokus penelitian, informan menjadi substansi utama. Informan dalam penelitian adalah orang atau pelaku yang benar-benar tahu dan menguasai masalah, serta terlibat langsung dengan masalah penelitian. Informan dalam penelitian ini adalah penonton serial Game of Thrones yang dipilih menggunakan metode purposive sampling, dengan jenis kelamin, usia, dan latar belakang pendidikan berbeda-beda dan domisili yang cukup beragam. Kriteria lain yang harus dimiliki informan antara lain adalah telah menonton minimal lima season (50 episode) Game of Thrones karena objek dari penelitian ini - kekerasan seksual dalam serial Game of Thrones - terlihat pada lima season pertama, kemudian berkurang pada season 6, serta agar penonton yang terpilih memahami perkembangan narasi dalam serial tersebut.

Subjek dalam penelitian ini tidak diarahkan pada jumlah, melainkan pada kasus yang sesuai dengan kekhususan penelitian. Namun, subjek juga tidak ditentukan secara pasti di awal penelitian, melainkan adanya penambahan informan yang dilakukan hingga data yang diperoleh mencapai titik jenuh (saturation point).

Sementara peneliti membatasi objek penelitian ini pada kekerasan seksual yang ditayangkan dalam serial televisi Game of Thrones. Peneliti memilih beberapa episode yang meliputi lima adegan kekerasan seksual, yang kemudian menjadi fokus dari objek penelitian. Adegan itu antara lain (1) pemerkosaan, (2) pelacuran sebagai kekerasan seksual, (3) seks sedarah, dan (4) hukuman bernuansa seksual.

Tiga unsur dalam analisis resepsi menurut Jensen (1999: 139) adalah pengumpulan data, analisis data, dan interpretasi data, yang kemudian dijadikan langkah-langkah 
penelitian untuk dilakukan oleh peneliti, yaitu (1) mengumpulkan data dari khalayak melalui wawancara mendalam untuk menggali bagaimana sebuah isi pesan media tertentu menstimulasi wacana yang berkembang dalam diri khalayak, (2) analisis dan interpretasi data khalayak dari wawancara mendalam yang dibuat transkrip, kemudian dibuat kategorisasi berdasarkan kode-kode yang muncul pada pembacaan yang diterjermahkan oleh subjek penelitian, dan pembacaan yang muncul dari khalayak (decoding) dibandingkan dengan analisis konten media (encoding) untuk dikelompokkan ke dalam macam-macam posisi pembaca, serta (3) pembacaan yang muncul kemudian dianalisis dengan mempertimbangkan kerangka pengetahuan yang meliputi proses pembacaan, seperti konteks sosial dan kultural yang melingkupi proses pemaknaan.

\section{PEMBAHASAN}

Berdasarkan hasil penelitian, rumusan makna produsen teks, dalam hal ini adalah creator dan show runner serial Game of Thrones, David Benioff dan D.B. Weiss, terhadap kekerasan seksual dalam serial tersebut dapat dibuat rinciannya menjadi beberapa fokus. Pertama, serial Game of Thrones dibuat dengan latar belakang yang berbasis pada abad pertengahan dimana derajat perempuan jauh di bawah laki-laki. Kedua, semua tokoh perempuan dalam serial Game of Thrones dapat dibagi menjadi dua kategori, yakni bangsawan dan pekerja seksual dimana menjadi pekerja atau budak seks kerajaan merupakan cara bertahan hidup bagi perempuan non-bangsawan pada masa itu. David Benioff juga mengungkapkan bahwa banyaknya adegan seksual dalam serial Game of Thrones ditujukan sebagai usaha mengeluarkan sisi pervert (cabul) dalam diri khalayak.

Rumusan produsen teks di atas kemudian dibandingkan dengan pembacaan khalayak terhadapnya untuk mengetahui posisi pembacaan khalayak. Khalayak memaknai adegan kekerasan seksual dalam serial Game of Thrones dalam caranya masing-masing yang dapat dikelompokkan menjadi enam (6) kategori pembacaan, yakni: (1) adegan kekerasan seksual yang ditampilkan adalah bentuk penggambaran budaya pada era medieval, (2) banyaknya adegaan vulgar dengan unsur kekerasan bertujuan sebagai sarana pemenuh hasrat seksual bagi penonton, (3) adegan kekerasan seksual yang ditampilkan adalah strategi yang dilakukan produser serial Game of Thrones untuk menarik khalayak, (4) adegan kekerasan seksual merupakan bagian penting dari cerita yang diperlukan untuk memperkuat karakter dari tokoh dalam cerita, (5) adegan kekerasan seksual yang ditampilkan adalah refleksi dari kehidupan yang terjadi di dunia nyata saat ini, serta (6) banyaknya adegan seksual yang ditampilkan terlalu berlebihan untuk disaksikan oleh orang Indonesia yang belum cukup berpendidikan dalam hal seksual (sexual education) maupun media.

Setelah mengetahui beragam pembacaan khalayak terhadap adegan kekerasan seksual dalam serial Game of Thrones yang difokuskan menjadi lima bagian, peneliti kemudian mengelompokkan hasil pembacaan tersebut ke dalam tiga posisi pembacaan. Seperti yang dikemukakan oleh Stuart Hall (2011: 136), tiga posisi pembacaan tersebut adalah dominant-hegemonic reading, negotiated reading, dan oppositional reading. Posisi masing-masing pembacaan khalayak akan diperoleh dengan cara melakukan komparasi antara pembacaan khalayak dengan rumusan makna dari produsen teks yang bersangkutan. 
Posisi pembacaan pertama, dominant-hegemonic reading, adalah posisi dimana pembaca sejalan dengan kode-kode program yang di dalamnya terkandung nilai-nilai, sikap, keyakinan, dan asumsi secara penuh menerima makna yang disodorkan dan dikehendaki oleh pembuat program. Oleh karena itu, khalayak dalam posisi ini memiliki keyakinan yang sama terhadap pesan atau makna yang dibuat oleh produsen teks.

Posisi pembacaan kedua, negotiated reading, adalah posisi dimana pembaca dalam batas-batas tertentu sejalan dengan kode-kode program dan pada dasarnya menerima makna yang disodorkan oleh produsen program, namun memodifikasinya sedemikian rupa sehingga mencerminkan posisi dan minat-minat pribadinya. Decoding dalam versi yang dinegosiasikan mengandung campuran unsur-unsur yang bersifat adaptif dan oposisional ditinjau dari berbagai segi, baik ideologi, keyakinan, maupun agama yang dianutnya.

Posisi pembacaan terakhir, yakni oppositional reading, adalah posisi dimana pembaca tidak sejalan dengan kode-kode program dan menolak makna atau pembacaan yang disodorkan, dan kemudian menentukan frame alternatif sendiri di dalam menginterpretasikan pesan atau makna dalam program. Dalam posisi pembacaan ini, khalayak menolak seluruh kode dan makna yang diciptakan oleh produsen teks untuk kemudian membuat interpretasi dengan pola berpikirnya sendiri.

Pembacaan terhadap banyaknya adegan kekerasan seksual dalam Game of Thrones terbagi menjadi tiga fokus, yakni kekerasan seksual dilatarbelakangi penggambaran dari era medieval dimana derajat perempuan jauh di bawah laki-laki, banyaknya adegan seksual bertujuan untuk mengeluarkan sisi pervert khalayak, dan perempuan pada era medieval berprofesi sebagai pekerja/budak seks sebagai cara hidup pada era medieval.

Berdasarkan komparasi antara rumusan makna produsen dengan pembacaan khalayak, dalam hal ini 8 orang informan yang menjadi subjek penelitian, peneliti membuat poin sebagai berikut: (1) mengenai pesan produsen yang mengungkapkan bahwa serial Game of Thrones dibuat dengan latar belakang pada era medieval, dimana derajat perempuan berada jauh di bawah laki-laki, 3 informan digolongkan dalam posisi dominanthegemonic, 4 informan digolongkan dalam posisi negotiated, dan hanya 1 informan yang digolongkan dalam posisi oppositional; (2) mengenai pesan produsen tentang banyaknya adegan seksual bertujuan untuk mengeluarkan sisi pervert dalam diri khalayak, 4 informan digolongkan ke dalam posisi dominant-hegemonic, 3 informan lainnya tergolong dalam posisi oppositional, dan 1 informan tergolong dalam posisi negotiated.; (3) mengenai pesan produsen bahwa berprofesi sebagai pekerja atau budak seks adalah cara hidup bagi perempuan non-bangsawan pada masa itu, sebanyak 5 informan tergolong dalam posisi negotiated, dan 3 informan lainnya tergolong dalam posisi dominant-hegemonic.

Khalayak dalam penelitian ini menginterpretasikan makna yang ada dalam serial Game of Thrones berdasarkan pemahamannya masing-masing. Aspek-aspek sosio kultural dan kemampuan intelektual pun memengaruhi cara informan menginterpretasikan pesan yang terkandung dalam teks media. Aspek sosio-kultural dan kemampuan intelektual ini mencakup nilai, norma, dan keyakinan yang dipegang oleh masing-masing informan.

Setiap khalayak memiliki otoritas sendiri dalam menerjemahkan berbagai pesan yang ditujukan dalam serial televisi ini. Adanya keberagaman dari segi pembacaan khalayak membuktikan bahwa setiap informan menginterpretasikan makna yang ada secara berbeda-beda. Pembacaan yang dilakukan oleh para informan juga bergantung pada latar 
belakang sosio-ekonomi, norma, budaya, serta keyakinan masing-masing. Hal inilah yang dapat disebut sebagai kerangka pengetahuan dalam studi resepsi khalayak yang meliputi Field of Experience dan Frame of Reference.

Pembacaan yang dihasilkan berasal dari pengetahuan dasar khalayak akan serial Game of Thrones serta pengalaman maupun pengetahuan khalayak yang berkaitan dengan kekerasan seksual. Delapan informan dalam penelitian ini memiliki pengetahuan akan Game of Thrones yang cukup luas karena telah memenuhi kriteria subjek yang telah ditetapkan sebelumnya, diantaranya adalah telah menonton Game of Thrones sedikitnya 20 episode. Bahkan, kedelapan informan seluruhnya telah menonton Game of Thrones hingga episode terakhir, yakni episode ke 60 .

Faktor pertama yang memengaruhi kerangka pengetahuan khalayak adalah faktor keyakinan atau agama. Khalayak yang beragama Islam lebih tegas dalam menunjukkan ketidaksetujuannya terhadap banyaknya adegan vulgar yang ditayangkan dalam serial Game of Thrones. Beberapa dari mereka meyakini tayangan dengan unsur seksual tersebut tidak sepantasnya menjadi konten dalam serial televisi yang dapat diakses dan disaksikan dengan mudah, apalagi ditambah banyaknya kekerasan seksual di dalamnya.

Faktor kedua adalah nilai-nilai sosiokultural. Aspek sosiokultural dapat diartikan sebagai segala sesuatu yang berkenaan dengan segi sosial dan budaya masyarakat. Sosiokultural juga dapat diartikan sebagai letak suatu wilayah atau negara berdasarkan keadaan sosial dan budaya daerah yang bersangkutan terhadap daerah di sekelilingnya. Dalam hal ini, khalayak Game of Thrones yang menjadi informan dalam penelitian ini sebagian besar tinggal di Indonesia, dimana budaya dan adat ketimuran yang ada masih terasa kental. Budaya timur kental dengan tutur kata yang lemah lembut dan sopan dalam bergaul maupun berpakaian, nilai inilah yang sedikit banyak memengaruhi pembacaan khalayak terhadap kekerasan sekusal yang ada dalam serial Game of Thrones. Adegan seksual yang ditayangkan banyak tidak dapat diterima dengan positif oleh khalayak di Indonesia. Berbeda halnya dengan khalayak yang terbiasa dengan budaya barat, mereka mengintepretasikan maraknya adegan bernuansa seksual yang ditayangkan dalam serial Game of Thrones sebagai 'bumbu' dari cerita yang ada.

Selain kedua faktor tersebut, latar belakang pendidikan khalayak juga berpengaruh terhadap interpretasi mereka atas rumusan teks yang diberikan. Tinggi atau rendahnya tingkat pendidikan memengaruhi cara khalayak melihat tayangan adegan seksual dalam Game of Thrones, yang dipersepsikan sebagai strategi produsen dalam meningkatkan rating serial tersebut, sebagai keunikan sendiri dari sebuah serial, maupun anggapan bahwa adegan seksual tersebut tidak perlu untuk ditayangkan. Bidang pendidikan yang dipelajari serta diminati oleh khalayak juga memengaruhi sejauh mana ataupun titik-titik fokus dalam serial yang menarik bagi khalayak. Khalayak yang memiliki minat pada seni akan tertarik pada detail, aspek artistik pada kostum, properti, dan hal-hal berbau seni lainnya. Sementara khalayak dengan latar belakang ilmu komunikasi akan lebih fokus terhadap unsur intrik pada cerita di dalam serial tersebut.

Pada dasarnya, khalayak meresepsikan suatu hal berdasarkan pengalaman dan pengetahuan intelektualnya masing-masing. Hal-hal yang menarik bagi khalayak bervariasi, dipengaruhi oleh minat dan bidang ketertarikannya masing-masing. Latar belakang khalayak. 


\section{SIMPULAN}

Ada beberapa poin simpulan yang dapat diambil dari penelitian ini, yaitu sebagai berikut.

Pertama, produsen teks merumuskan adegan seksual yang ditampilkan secara eksplisit dalam serial Game of Thrones sebagai hiburan semata serta usaha untuk mengeluarkan sisi pervert dalam diri khalayak. Banyaknya adegan kekerasan seksual yang ditampilkan juga merupakan penggambaran kehidupan dengan latar belakang era medieval. Produsen ingin khalayak memahami hidup manusia pada masa itu, salah satunya dengan menjadikan seks sebagai cara bertahan hidup. Beberapa adegan pemerkosaan yang ditampilkan tidak dirumuskan oleh produsen teks sebagai bentuk kekerasan seksual, melainkan produsen menyelipkan makna tersendiri yang diharapkan diterima oleh para khalayaknya. Bermain dengan sisi emosional penonton, seperti menumbuhkan empati dan mendukung salah satu karakter dalam serial merupakan salah satu tujuan dari berbagai adegan kekerasan seksual yang ditampilkan.

Kedua, Pembacaan khalayak terhadap kekerasan seksual menunjukkan hasil yang beragam, mulai dari yang sejalan hingga bertolakbelakang dengan rumusan makna produsen teks. Penelitian ini menghasilkan ketiga posisi pembacaan dari dominanthegemonic, negotiated, hingga oppositional reading. Jumlah posisi pembacaan yang paling banyak adalah negotiated, diikuti dengan oppositional, dan terakhir dominant-hegemonic reading, Hal ini menunjukkan bahwa rumusan makna yang dikehendaki produsen teks belum benar-benar tersampaikan secara baik.

Ketiga, Pembacaan khalayak terhadap kekerasan seksual dalam serial Game of Thrones didasari oleh kerangka pengetahuan dan pengalamannya masing-masing. Aspek keyakinan, nilai-nilai sosio kultural, latar belakang pendidikan, serta lingkungan pergaulan adalah faktor-faktor yang mempengaruhi pembacaan khalayak.

Selain itu, berdasarkan pembahasan dan simpulan yang ada, peneliti juga mengajukan beberapa saran.

Saran pertama adalah agar sebaiknya produsen teks serial Game of Thrones melakukan khalayak dalam menentukan konten selanjutnya supaya makna dan pesan yang diciptakan dapat tersampaikan dengan baik. Saran ini juga ditujukan kepada para produsen teks media lainnya sebelum merumuskan konten media agar sekiranya konten yang diciptakan sesuai dengan khalayak yang ditargetkan. Konten media lebih baik apabila dikaitkan dengan konteks kultural dan budaya dimana program tersebut akan ditayangkan.

Selanjutnya, karena studi literature mengenai analisis resepsi masih terbilang sangat minim, peneliti menyarankan agar kajian mengenai analisis resepsi maupun penelitian dengan menggunakan metode analisis resepsi untuk lebih ditingkatkan dan dikembangkan.

\section{DAFTAR PUSTAKA}

Baran, S. J. (2010). Teori Komunikasi Massa Dasar, Pergolakan, dan Masa Depan. Jakarta: Salemba Humanika.

Bungin, B. (2007). Penelitian Kualitatif: Komunikasi, Ekonomi, Kebijakan Publik, dan Ilmu Sosial Lainnya. Jakarta: Kencana. 
Burton, G. (2008). Media dan Budaya Populer. Yogyakarta: Jalasutra.

Barker, C. (2008). Cultural Studies; Teori dan Praktik. Yogyakarta: Kreasi Wacana.

Frankel, Valerie Estelle. (2014). Women in Game of Thrones: Power, Conformity, and Resistance. Jefferson, NC: McFarland \& Co.

Hall, S. (2011). Budaya Media Bahasa. Yogyakarta: Jalasutra.

Ida, Rachmah. (2014). Metode Penelitian Studi Media dan Kajian Budaya. Jakarta: Kencana.

Jensen, K. B. (1999). A Handbook of Qualitative Methodologies for Mass Communication Research: Media Audiences. London: Rotledge.

McQuail, D. (1997). Audience Analysis. London: SAGE Publications.

Moleong, L. J. (2008). Metodologi Penelitian Kualitatif. Bandung: Rosdakarya.

Mulyana, D. (2008). Metode Penelitian Komunikasi. Bandung: Rosdakarya.

Patton, Michael Quinn. (1987). Qualitative Eduacation Methods. Beverly Hills: SAGE Publications.

Stokes, Jane. (2006). How to Do Media and Culture Studies: Pandungan untuk Melaksanakan Penelitian dalam Kajian Media dan Budaya. Yogyakarta: Bentang.

Storey, J. (2007). Pengantar Komprehensif Teori dan Metode Cultural Studies dan Kajian Budaya Pop. Yogyakarta: Jalasutra.

Sugiyono. (2012). Memahami Penelitian Kualitatif. Bandung: Alfabeta.

Sunarto. (2009). Televisi, Kekerasan, dan Perempuan. Jakarta: Penerbit Buku Kompas.

\section{Sumber Jurnal:}

Hadi, I.P. (2009). Penelitian Khalayak dalam Perspektif Reception Analysis. Jurnal Ilmiah SCRIPTURA, 3 (1), 1-7. 
